\title{
Anti-inflammatory effects of bone marrow mesenchymal stem cells on mice with Alzheimer's disease
}

\author{
YAN WEI, ZHAOHONG XIE, JIANZHONG BI and ZHENGYU ZHU \\ Department of Neurology Medicine, Second Hospital of Shandong University, Jinan, Shandong 250033, P.R. China
}

Received April 19, 2018; Accepted September 13, 2018

DOI: $10.3892 / \mathrm{etm} .2018 .6857$

\begin{abstract}
Anti-inflammatory effects of bone marrow mesenchymal stem cells (BMSCs) on mice with Alzheimer's disease (AD) were investigated. Twenty amyloid precursor protein (APP)/presenilin-1 (PS1) double transgenic mice were randomly divided into two groups: the AD control group and the stem cell treatment group. The normal control group consisted of 10 non-transgenic mice. The stem cell treatment group was injected with BMSCs, and the two control groups were given the same volume of normal saline. The Morris water maze test was used to compare the memory function of mice, and the relative expression levels of $\beta$-site APP cleaving enzyme 1 (BACE1) and $\alpha$-2-macroglobulin (A2M) genes were detected by fluorescence quantitative polymerase chain reaction (qPCR). Amyloid $\beta$ (A $\beta) 1-42$ content in brain tissues of mice and inflammatory cytokines, interleukin (IL)-1, IL-2, IL-10, tumor necrosis factor- $\alpha$ (TNF- $\alpha$ ), and interferon- $\gamma($ IFN- $\gamma)$ were detected using enzyme-linked immunosorbent assay (ELISA). Compared with that in the AD control group, the escape latency in the water maze in the stem cell treatment group was shortened, the time of crossing the ring for the first time was decreased, but the frequency of crossing the ring was increased $(\mathrm{P}<0.05)$. A $\beta 1-42$ content in the AD control group was higher than that in the stem cell treatment group and the normal control group $(\mathrm{P}<0.05)$. The relative expression level of BACE1 gene in the stem cell treatment group was lower than that in the $\mathrm{AD}$ control group $(\mathrm{P}<0.05)$, but that of $\mathrm{A} 2 \mathrm{M}$ gene was increased $(\mathrm{P}<0.05)$. At 14 days after treatment, the contents of IL-1, IL-2, TNF- $\alpha$ and IFN- $\gamma$ in blood in the stem cell treatment group were lower than those in the AD control group $(\mathrm{P}<0.05)$. Human BMSCs can ameliorate the symptoms of AD by decreasing the levels of inflammatory cytokines and regulating the expression of A $\beta$-related genes.
\end{abstract}

Correspondence to: Dr Zhengyu Zhu, Department of Neurology Medicine, Second Hospital of Shandong University, 247 Beiyuan Avenue, Jinan, Shandong 250033, P.R. China

E-mail: doctor_wy2005@163.com

Key words: bone marrow mesenchymal stem cells, Alzheimer's disease, inflammatory cytokines, amyloid precursor protein/presenilin-1 mouse

\section{Introduction}

Alzheimer's disease (AD) is a neurological type of neurodegenerative disease. It is mainly caused by aging and apoptosis of nerve cells affected by internal and external environmental factors, and a large amount of degeneration and loss of dopaminergic neurons. AD mainly occurs in the elderly at the age of $>65$ years and is manifested as memory loss and cognitive problems resulting in serious inconvenience of their daily lives $(1,2)$. In Europe, the United States and other countries, $\mathrm{AD}$ is a major neurological disease that causes the death of the elderly. The number of deaths from AD in China also ranks in the top 10 countries (3). At present, popular drugs used in the treatment of AD on the market do not substantially improve the loss of dopaminergic neurons, especially in patients with advanced AD (4). However, AD patients are often accompanied by an increase of inflammatory cytokines in the body and brain, and inflammation is considered by many researchers as one of the key causes of neurodegenerative diseases that trigger AD and dementia. Therefore, many traditional Chinese and Western anti-inflammatory drugs also appear in various studies on treating $\mathrm{AD}(5,6)$. Stem cells can be renewable and differentiable, and thus considered to be a promising material for the treatment of AD. Bone marrow mesenchymal stem cells (BMSCs) have been characterized as having a wide range of sources, easiness to draw materials, simple to culture and difficult in tumor formation in vivo, thereby differentiating them into dopaminergic neurons in brain tissues to make up for the loss of cells caused by $\mathrm{AD}$, thus fundamentally treating AD. (7-9). In this study, the improvement of AD symptoms by BMSCs and the effects of BMSCs on in vivo inflammatory cytokines were observed and investigated through studying AD mice.

\section{Materials and methods}

Experimental animals. A total of 20 amyloid precursor protein (APP)/presenilin-1 (PS1) double transgenic mice (Beijing Biocytogen Co., Ltd., Beijing, China) were randomly divided into two groups: the AD control group $(n=10)$ and the stem cell treatment group $(n=10)$. Ten $C 57$ black 6 bred in the Jackson Laboratory (C57BL/6J) non-transgenic mice were included in the normal control group. The mice were kept in cages with controlled temperature and light cycles $\left(24^{\circ} \mathrm{C}\right.$ and $12 / 12$ light cycles) and had free access to food and water. The humidity was $60 \pm 10 \%$. There were no statistically significant 
differences in age, sex and weight among the three groups of mice $(\mathrm{P}>0.05)$, and the data were comparable (Table I). The study was approved by the Ethics Committee of the Second Hospital of Shandong University (Jinan, China).

Reagents. Cell culture Dulbecco's modified Eagle's medium (DMEM), fetal bovine serum (FBS) and trypsin powder were purchased from Gibco (Gibco; Thermo Fisher Scientific, Inc., Waltham, MA, USA). RNAiso Plus, PrimeScript ${ }^{\circledR}$ Real-Time (RT) Reagent kit with genomic deoxyribonucleic acid (gDNA) Eraser (Perfect Real-time) and SYBR ${ }^{\circledR}$ Premix Ex $\mathrm{Taq}^{\mathrm{TM}}$ II [Tli ribonuclease H (RNase H) Plus] were purchased from Takara Biotechnology Co., Ltd. (Dalian, China). Enzyme-linked immunosorbent assay (ELISA) kits were purchased from Zhongshan Golden Bridge Biotechnology Co., Ltd. (Zhongshan Golden Bridge Biotechnology Co., Ltd.; OriGene Technologies, Beijing, China).

Separation and culture of BMSCs. Operations were conducted under aseptic environment. A 200-mesh sieve was used for cell screening. The parameters of cell and tissue centrifugation for the separation process were $800 \mathrm{x} \mathrm{g} / \mathrm{min}$ at $4^{\circ} \mathrm{C}$ for 3 min. Phosphate-buffered saline (PBS) was used for thorough washing, as the clearer and cleaner the solution was the better the results would be. The washing was conducted each time for approximately $\geq 2$ times. In addition, the number of living cells was determined using trypan blue staining, and counted using a cell counter. Cell culture reagents, consumable items and environmental conditions (temperature and humidity) were strictly adjusted in accordance with the characteristics of the cell growth. After the cell growth area reached $\sim 80 \%$ of the total area of the flat bottom, the passage could be performed, and the passage ratio would be determined according to the amount of cells required for the next experiment.

Determination by flow cytometry. Flow cytometry detection (10): i) the test objects were the fourth-generation BMSCs. ii) The centrifugation parameters for the preparation of the flow cytometry samples were $800 \mathrm{x}$ g/min at $4^{\circ} \mathrm{C}$ for $3 \mathrm{~min}$. iii) The cells were mixed and suspended in PBS, and the number of cells was $1-2 \times 10^{6}$. iv) Surface antibody (4 $\left.\mu 1\right)$ was added in each tube and incubated at $25^{\circ} \mathrm{C}$ for 30 min avoiding light. v) PBS $(500 \mu \mathrm{l})$ was used to wash the cells. Then the cells were collected and centrifuged at $800 \mathrm{x} \mathrm{g}$ for $5 \mathrm{~min}$. The supernatant was discarded. vi) PBS $(500 \mu \mathrm{l})$ was added for resuspension. Then the cells were added to the BD FACSCalibur flow cytometer (BD Biosciences, Franklin Lakes, NJ, USA). vii) The cell flow rate was moderate, and the cell population conforming to the characteristics was selected according to forward scatters (FSCs) and side scatters (SSCs). viii) The voltage was adjusted according to the graphics to make the graphics easy to observe and for better display results.

Tail intravenous injection of mice. BMSC suspension was prepared. Stem cells for intravenous injection were digested from the adherent state to the suspended state, and washed with normal saline, followed by centrifugation at $800 \mathrm{x} \mathrm{g} / \mathrm{min}$ at $4^{\circ} \mathrm{C}$ for 3 min twice and filtering by a cell sieve filter once. Then the filtered stem cell suspension was immediately placed on ice and transferred to the intravenous injection site. The mice
Table I. Comparisons of general data among the three groups of mice (mean $\pm \mathrm{SD})$.

\begin{tabular}{lcccc}
\hline Group & Age & $\begin{array}{c}\text { Weight } \\
(\mathrm{g})\end{array}$ & $\begin{array}{c}\text { Sex } \\
\text { (male/female) }\end{array}$ \\
\hline Normal control & 10 & $7.2 \pm 0.3$ & $24.2 \pm 4.2$ & $5 / 5$ \\
AD control & 10 & $7.1 \pm 0.2$ & $23.4 \pm 3.9$ & $5 / 5$ \\
Treatment & 10 & $6.9 \pm 0.2$ & $23.7 \pm 3.8$ & $5 / 5$ \\
P-value & - & $>0.05$ & $>0.05$ & $>0.05$ \\
\hline
\end{tabular}

$\mathrm{AD}$, Alzheimer's disease.

Table II. qPCR primer sequences.

\begin{tabular}{ll}
\hline Gene name & \multicolumn{1}{c}{ Primer sequence } \\
\hline BACE1 & F: 5'-3'CAAGTTCATTACCTCCCTA \\
& R: 5'-3'CGACTGACCCTTGTGG \\
A2M & F: 5'-3'AAAGGAAATCGCATCG \\
& R: 5'-3'CATGTTCATTGTCACGGTTT \\
$\beta$-actin & F: 5'-3'TCAGGTCATCACTATCGGCAAT \\
& R: 5'-3'ACGCAAATGTGGGAAAGAAA
\end{tabular}

qPCR, quantitative polymerase chain reaction; BACE1, $\beta$-site APP cleaving enzyme 1; A2M, $\alpha$-2-macroglobulin; F, forward; R, reverse.

aged 7 weeks were fixed in a rat fixator, and $1 \mathrm{ml}$ suspension containing $2 \times 10^{6}$ stem cells was injected using a $2.5 \mathrm{ml}$ syringe each time. The normal control group and the AD control group were injected with the same volume of normal saline once a day.

Morris water maze test (11). The experiment began on the 22nd day after gavage treatment and was divided into two stages. In the first stage, mice received 3-day continuous training twice a day, and the experimental time was not recorded. In the second phase, mice underwent the fixed-position cruise for 5 consecutive days, once daily: the mice were placed facing the wall of the pool and put in pools from different quadrants to record the time they searched for the underwater surface hidden in the third quadrant (escape latency). If the mice could not find the platform within $90 \mathrm{sec}$, they were guided to the platform for a rest for $30 \mathrm{sec}$, and the latency was recorded as $90 \mathrm{sec}$. At the end of fixed-position cruise, the space exploration experiment was conducted for 1 day: the platform was withdrawn, the time occupied by the mice in the third quadrant within the $90 \mathrm{sec}$ and the frequency of crossing the original platform were recorded. Morris water maze image automatic monitoring and processing system was applied to collect and process data.

Indicator detection. ELISA kits were used to detect the contents of interleukin (IL)-1, IL-2, IL-10, tumor necrosis factor- $\alpha$ (TNF- $\alpha)$, and interferon- $\gamma($ IFN- $\gamma)$ in plasma as well as amyloid $\beta$ (A $\beta) 1-42$ content in brain tissues. The relative expression levels of $\beta$-site APP cleaving enzyme 1 (BACE1) and $\alpha$-2-macroglobulin (A2M) genes were detected by fluorescence quantitative polymerase chain reaction (qPCR), and the 

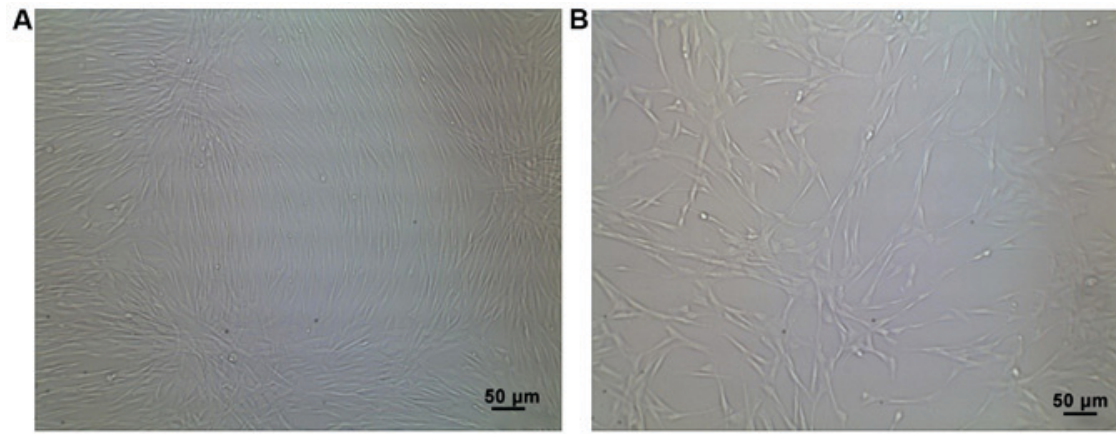

Figure 1. Separation and culture of BMSCs. There is no difference in cell morphology between cells at (A) P0 and those at (B) P4. BMSCs, bone marrow mesenchymal stem cells; P0, passage 0 ; P4, passage 4 .
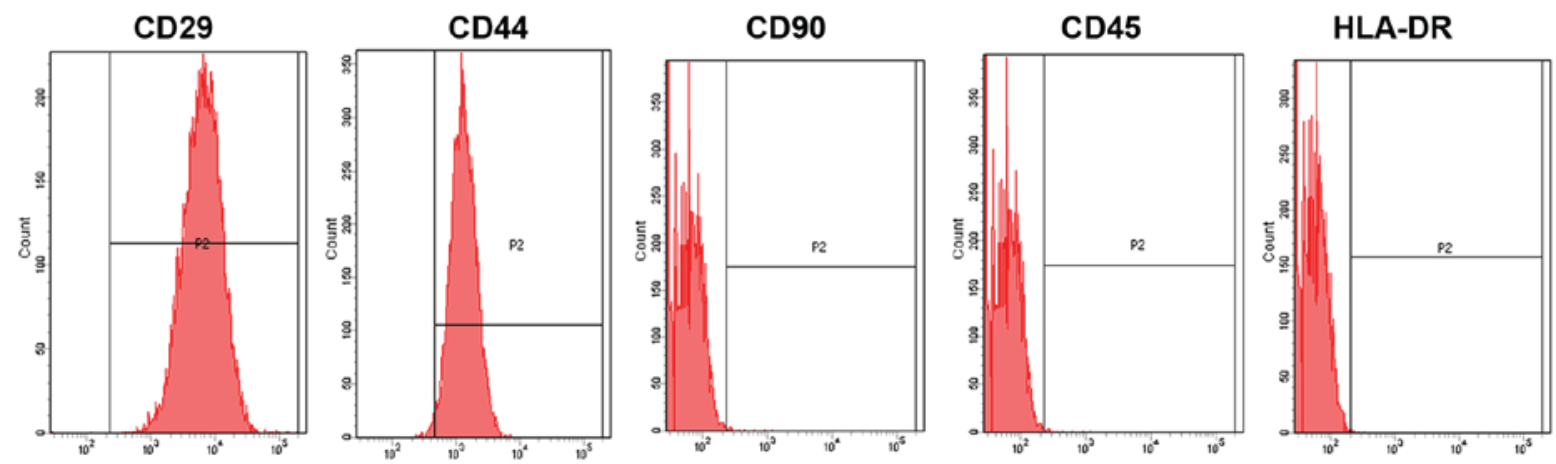

Figure 2. Identification results of BMSCs by a flow cytometer. CD29, CD44 and CD90 are positive, whereas CD45 and HLA-DR are negative. BMSCs, bone marrow mesenchymal stem cells; CD, cluster of differentiation; HLA-DR, human leukocyte antigen antigen-D-related.

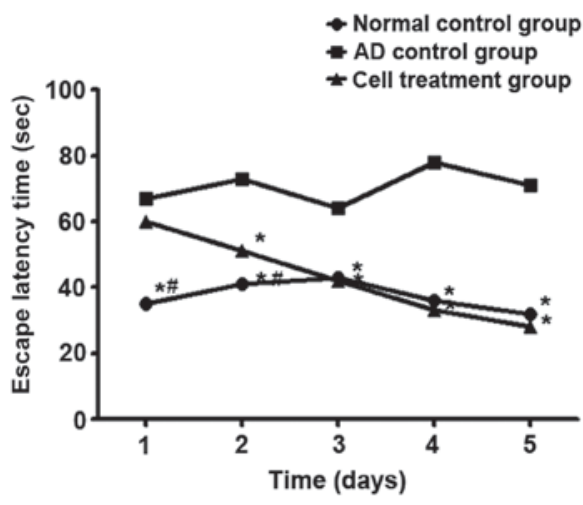

Figure 3. Effect of stem cells on the escape latency time of AD mice. ${ }^{*} \mathrm{P}<0.05$ compared with the $\mathrm{AD}$ group. ${ }^{\prime \prime} \mathrm{P}<0.05$, compared with the cell treatment group. AD, Alzheimer's disease.

primer sequences are shown in Table II. mRNA levels were determined by Bio-Rad CFX96 fluorescence qPCR detection system (Bio-Rad Laboratories, Inc., Hercules, CA, USA). The thermocycling conditions were as follows: $5^{\circ} \mathrm{C}$ for $5 \mathrm{~min} ; 94^{\circ} \mathrm{C}$ for $10 \mathrm{sec}, 50^{\circ} \mathrm{C}$ for $30 \mathrm{sec}, 40 \mathrm{cycles} ; 72^{\circ} \mathrm{C}$ for another $10 \mathrm{~min}$. The image was analyzed with GraphPad Prism statistical software (GraphPad Software, Inc., La Jolla, CA, USA).

Statistical methods. All data were processed using Statistical Product and Service Solutions (SPSS) 16.0 software (Cabit Information Technology Co., Ltd., Shanghai, China). Measurement data were expressed as mean $\pm \mathrm{SD}$, and the
Table III. The time of crossing the ring for the first time and its frequency $($ mean $\pm \mathrm{SD})$.

\begin{tabular}{lcc}
\hline Group & $\begin{array}{c}\text { Time of crossing } \\
\text { the ring for } \\
\text { the first time (sec) }\end{array}$ & $\begin{array}{c}\text { Frequency of } \\
\text { crossing the } \\
\text { ring (times) }\end{array}$ \\
\hline Normal control & $16.32 \pm 9.32$ & $4.8 \pm 1.3$ \\
AD control & $27.32 \pm 12.43$ & $1.5 \pm 0.4$ \\
Stem cell treatment & $22.38 \pm 11.54^{\mathrm{a}}$ & $4.9 \pm 0.9^{\mathrm{a}}$ \\
\hline
\end{tabular}

${ }^{\mathrm{a}} \mathrm{P}<0.05$, compared with the $\mathrm{AD}$ control group. $\mathrm{AD}$, Alzheimer's disease.

comparison of mean was conducted using t-test and one-way analysis of variance. The post hoc test used was LSD test. $\mathrm{P}<0.05$ was considered to indicate a statistically significant difference.

\section{Results}

Separation and identification of BMSCs. BMSCs were successfully isolated. They were spindle-shaped and spirally arranged, and grew adhering to the culture dishes (Fig. 1). The obtained BMSCs were identified using a flow cytometer, which revealed that cluster of differentiation (CD)29, CD44 and CD90 were positive, whereas CD45 and human leukocyte antigen antigen-D-related (HLA-DR) were negative (Fig. 2). 
Table IV. Comparison of several inflammatory cytokines in blood (mean \pm SD).

\begin{tabular}{|c|c|c|c|c|c|}
\hline Group & IL-1 (pg/ml) & IL-2 (pg/ml) & $\mathrm{TNF}-\alpha(\mathrm{pg} / \mathrm{ml})$ & $\mathrm{IFN}-\gamma(\mathrm{pg} / \mathrm{ml})$ & $\mathrm{IL}-10(\mathrm{pg} / \mathrm{ml})$ \\
\hline Normal control & $43.36 \pm 12.32$ & $59.33 \pm 21.32$ & $49.55 \pm 19.34$ & $39.44 \pm 15.21$ & $54.22 \pm 24.54$ \\
\hline AD control & $143.21 \pm 34.21$ & $121.32 \pm 12.43$ & $109.22 \pm 22.12$ & $108.23 \pm 35.21$ & $41.21 \pm 19.32$ \\
\hline Stem cell treatment & $53.21 \pm 19.43^{\mathrm{a}}$ & $67.35 \pm 21.11^{\mathrm{a}}$ & $55.21 \pm 20.32^{\mathrm{a}}$ & $44.43 \pm 19.54^{\mathrm{a}}$ & $47.43 \pm 17.43$ \\
\hline
\end{tabular}

${ }^{a} \mathrm{P}<0.05$, compared with the AD control group. AD, Alzheimer's disease; IL, interleukin; TNF- $\alpha$, tumor necrosis factor- $\alpha$; IFN- $\gamma$, interferon- $\gamma$.
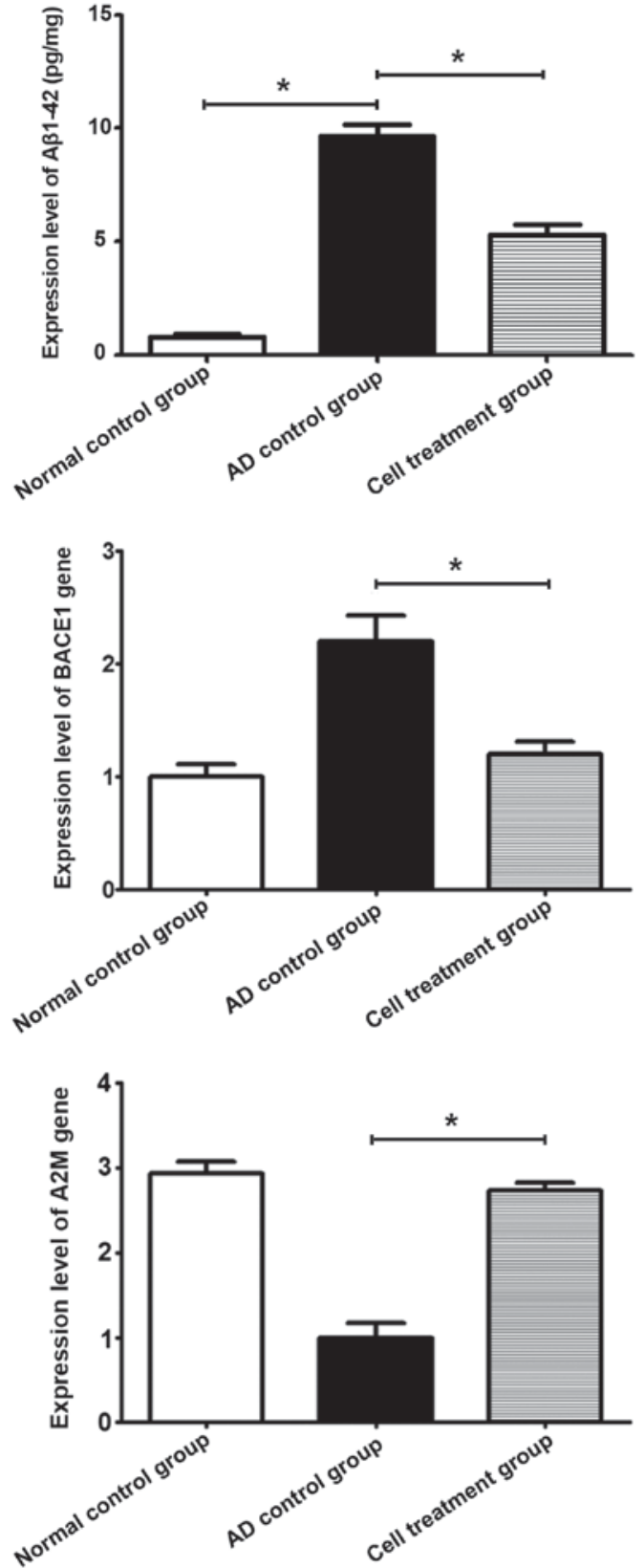

Figure 4. Detection of $A \beta 1-42$ content via ELISA reveals that $A \beta 1-42$ content in the AD control group is higher than that in the stem cell treatment and the normal control group $\left({ }^{*} \mathrm{P}<0.05\right)$. Detection of the relative expression levels of BACE1 and A2M genes in brain tissues was performed using qPCR. The expression level of BACE1 in the stem cell treatment group is lower than that in the AD control group ( $\mathrm{P}<0.05)$, while the expression level of $\mathrm{A} 2 \mathrm{M}$ gene was increased in the stem cell treatment group compared to that in the AD control group $\left({ }^{*} \mathrm{P}<0.05\right)$. A $\beta$, amyloid $\beta$; AD, Alzheimer's disease; BACE1, $\beta$-site APP cleaving enzyme 1; A2M, $\alpha$-2-macroglobulin; qPCR, quantitative polymerase chain reaction.
Comparison of memory function using the water maze test. From day 2, the escape latency in the water maze in the stem cell treatment group was shortened compared with that in the AD control group $(\mathrm{P}<0.05)$. From day 3 , there was no significant difference in the escape latency between the stem cell treatment group and the normal control group (P>0.05) (Fig. 3). The space exploration experiment showed that the time of crossing the ring for the first time in the stem cell treatment group was shorter than that in the AD control group $(\mathrm{P}<0.05)$, but the frequency was higher than that in the $\mathrm{AD}$ control group $(\mathrm{P}<0.05)$ (Table III).

A $\beta 1-42$ content and the relative expression levels of BACE1 and $A 2 M$ genes in brain tissues. A $\beta 1-42$ content in the AD control group was higher than that in the stem cell treatment group and the normal control group $(\mathrm{P}<0.05)$. The expression level of BACE1 in the stem cell treatment group was lower than that in the AD control group $(\mathrm{P}<0.05)$, while the expression level of A2M gene was increased in the stem cell treatment group compared to that in the AD control group $(\mathrm{P}<0.05)$ (Fig. 4).

Comparison of inflammatory cytokines between the three groups. At 14 days after treatment, the contents of IL-1, IL-2, TNF- $\alpha$ and IFN- $\gamma$ in blood in the stem cell treatment group were lower than those in the AD control group $(\mathrm{P}<0.05)$ (Table IV).

\section{Discussion}

AD has been characterized as a refractory disease worldwide and has long been a hotspot in the field of neuromedicine. Research on AD mainly focuses on the pathogenesis and treatment of the disease. The pathogenesis of AD is very complex, and the two currently-recognized theories are the reduction of cholinergic and the increase of $A \beta$ protein $(12,13)$. AD is treated mainly through drug actions on different neurotransmitter systems, so as to enhance the high-level activities of the central nervous system, reduce the symptoms occurring in the disease process, and delay the further development of dementia. However, most of the oral drugs exert certain effects in the treatment of AD in the early stage, but in the late stage, due to the large-scale decline of nerve cells in the hippocampus, drugs cannot fully pass the blood-brain barrier and exert few effects (14). In addition, $\mathrm{AD}$ is often accompanied by an increase of inflammatory cytokines, causing other complications, so it is also treated by a combination of multiple drugs (15). As a bioactive 
material, stem cells can be transformed into nerve cells by environmental stimuli to make up for the lack of original nerve cells, and they can be expanded in vivo to some extent so that the therapeutic effects endure longer. Besides, MSCs can also secrete factors that promote cell growth such as epidermal growth factor (EGF), vascular endothelial growth factor (VEGF) and insulin-like growth factor (IGF) under the action of paracrine and reduce the complications such as inflammation caused by AD $(16,17)$. Compared with embryonic stem cells, BMSCs, as a type of stem cells, are easier to obtain and to be isolated and cultured in vitro, and it is not easy for them to form tumors. Therefore, BMSCs have the advantages of low cost and high safety.

Han and $\mathrm{He}$ (18) treated A $\beta$ modeling Sprague-Dawley (SD) rats with MSCs in the umbilical cord. At 14 days after injection, the water maze test demonstrated that the frequency of mice in stem cell treatment group crossing the target quadrant was significantly increased. Some studies have pointed out that if stem cells are induced into neural stem cells in vitro, the direct injection of neural stem cells into the hippocampus of the brain will be more effective in the treatment of AD, but the difficulty lies in how to inject neural stem cells into a designated place and avoid trauma to the brain (19). It was found in the study of Farina et al (20) that BMSCs can attenuate the memory impairment of $A \beta$ deposits and stimulate the signal pathways of the primary tumor, change the expression levels of relevant genes, and inhibit apoptosis of nerve cells. Other studies have revealed that the occurrence process of $\mathrm{AD}$ is accompanied by inflammation, which can cause inflammation responses, resulting in changes in the in vivo contents of some factors associated with the verification. This study showed that the escape latency in the water maze in the stem cell treatment group was shortened, the time of mice crossing the ring for the first time was reduced, and the frequency of crossing the ring was increased. The relative expression level of BACE1 gene in the stem cell treatment group was decreased compared with that in the AD control group, while that of A2M gene was increased. The increased level of BACE1 gene would produce more encephaloclastic $\mathrm{A} \beta$ proteins, while $\mathrm{A} 2 \mathrm{M}$ gene encoded inhibitors that eliminated $A \beta$ proteins, and helped eliminate $A \beta$ proteins. However, at 14 days after treatment, $A \beta 1-42$ content in brain tissues in the stem cell treatment group was lower than that in the AD control group, and the expression levels of IL-1, IL-2, TNF- $\alpha$ and IFN- $\gamma$ in blood and hippocampus tissues in the stem cell treatment group were lower than those in the AD control group.

In conclusion, human BMSCs can ameliorate the symptoms of AD by decreasing the level of inflammatory cytokines and regulating the expression levels of $A \beta$-related genes.

\section{Acknowledgements}

Not applicable.

\section{Funding}

The study was supported by the Fundamental Research Funds of Shandong University (2016JC022) and the Foundation of the Second Hospital of Shandong University (S2014010007).

\section{Availability of data and materials}

The datasets used and/or analyzed during the current study are available from the corresponding author on reasonable request.

\section{Authors' contributions}

YW wrote the manuscript and was responsible for the separation and culture of BMSCs. ZX prepared the mice and was also involved in the conception of the study. JB assisted with flow cytometry. ZZ performed Morris water maze test. All authors read and approved the final manuscript.

\section{Ethics approval and consent to participate}

The study was approved by the Ethics Committee of the Second Hospital of Shandong University (Jinan, China).

\section{Patient consent for publication}

Not applicable.

\section{Competing interests}

The authors declare that they have no competing interests.

\section{References}

1. Bahaeddin Z, Yans A, Khodagholi F and Sahranavard S: Dietary supplementation with Allium hirtifolium and/or Astragalus hamosus improved memory and reduced neuro-inflammation in the rat model of Alzheimer's disease. Appl Physiol Nutr Metab 43: 558-564, 2018.

2. Elnagar MR, Walls AB, Helal GK, Hamada FM, Thomsen MS and Jensen AA: Probing the putative $\alpha 7 \mathrm{nAChR} / \mathrm{NMDAR}$ complex in human and murine cortex and hippocampus: Different degrees of complex formation in healthy and Alzheimer brain tissue. PLoS One 12: e0189513, 2017.

3. Swaminathan A and Jicha GA: Nutrition and prevention of Alzheimer's dementia. Front Aging Neurosci 6: 282, 2014.

4. Mohamad Nasir NF, Zainuddin A and Shamsuddin S: Emerging roles of sirtuin 6 in Alzheimer's disease. J Mol Neurosci 64: 157-161, 2018.

5. Momtaz S, Hassani S, Khan F, Ziaee M and Abdollahi M: Cinnamon, a promising prospect towards Alzheimer's disease. Pharmacol Res 130: 241-258, 2018.

6. Vinceti M, Chiari A, Eichmüller M, Rothman KJ, Filippini T, Malagoli C, Weuve J, Tondelli M, Zamboni G, Nichelli PF, et al: A selenium species in cerebrospinal fluid predicts conversion to Alzheimer's dementia in persons with mild cognitive impairment. Alzheimers Res Ther 9: 100, 2017.

7. Hagl S, Heinrich M, Kocher A, Schiborr C, Frank J and Eckert GP: Curcumin micelles improve mitochondrial function in a mouse model of Alzheimer's disease. J Prev Alzheimers Dis 1: 80-83, 2014

8. Grundman M: Alzheimer's disease drug development: Trial-ready cohorts should help. J Prev Alzheimers Dis 1: 69-70, 2014.

9. Bateman RJ and Morris JC: A new era: Disease modifying Alzheimer disease prevention trials. J Prev Alzheimers Dis 1: 68, 2014.

10. Hu X, Qu Y, Chu Q, Li W and He J: Investigation of the neuroprotective effects of Lycium barbarum water extract in apoptotic cells and Alzheimer's disease mice. Mol Med Rep 17: 3599-3606, 2018.

11. Wang P, Guo Q, Zhou Y, Chen K, Xu Y, Ding D, Hong Z and Zhao Q: Lack of association between triggering receptor expressed on myeloid cells 2 polymorphism rs75932628 and late-onset Alzheimer's disease in a Chinese Han population. Psychiatr Genet 28: 16-18, 2018. 
12. Flanagan KJ, Copland DA, Chenery HJ, Byrne GJ and Angwin AJ: Semantic feature disturbance in Alzheimer disease: Evidence from an object decision task. Cogn Behav Neurol 30 159-171, 2017.

13. Roland KP and Chappell NL: Caregiver experiences across three neurodegenerative diseases: Alzheimer's, Parkinson's, and Parkinson's with dementia. J Aging Health: Oct 1, 2017 (Epub ahead of print)

14. Botchway BOA, Moore MK, Akinleye FO, Iyer IC and Fang M: Nutrition: Review on the possible treatment for Alzheimer's disease. J Alzheimers Dis 61: 867-883, 2018.

15. Wang SS, Jia J and Wang Z: Mesenchymal stem cell-derived extracellular vesicles suppresses iNOS expression and ameliorates neural impairment in Alzheimer's disease mice. J Alzheimers Dis 61: 1005-1013, 2018.

16. Saksida T, Koprivica I, Vujičić M, Stošić-Grujičić S, Perović M, Kanazir S and Stojanović I: Impaired IL-17 production in gut-residing immune cells of 5xFAD mice with Alzheimer's disease pathology. J Alzheimers Dis 61: 619-630, 2018.

17. Eldholm RS, Barca ML, Persson K, Knapskog AB, Kersten H, Engedal K, Selbaek G, Braekhus A, Skovlund E and Saltvedt I: Progression of Alzheimer's disease: A longitudinal study in Norwegian Memory Clinics. J Alzheimers Dis 61: 1221-1232, 2018.
18. Han $\mathrm{X}$ and $\mathrm{He} \mathrm{G}$ : Toward a rational design to regulate $\beta$-amyloid fibrillation for Alzheimer's disease treatment. ACS Chem Neurosci 9: 198-210, 2018.

19. Harding A, Gonder U, Robinson SJ, Crean S and Singhrao SK: Exploring the association between Alzheimer's disease, oral health, microbial endocrinology and nutrition. Front Aging Neurosci 9: 398, 2017

20. Farina E, Baglio F, Pomati S, D'Amico A, Campini IC, Di Tella S, Belloni G and Pozzo T: The mirror neurons network in aging, mild cognitive impairment, and Alzheimer disease: A functional MRI study. Front Aging Neurosci 9: 371, 2017.

This work is licensed under a Creative Commons Attribution-NonCommercial-NoDerivatives 4.0 International (CC BY-NC-ND 4.0) License. 